\title{
Assessment of MT-279 compound effect on physical endurance of rats under conditions of chronic hypokinesia
}

\author{
Andrit Saienko ${ }^{1}$, Natalia Voloshchuk ${ }^{1}$, Olena Toziuk ${ }^{2}$, \\ Olena Kryvoviaz ${ }^{2}$, Serhit Kryvoviaz ${ }^{3}$, Vasyl Koval ${ }^{2}$
}

\begin{abstract}
${ }^{1}$ Department of Pharmacology, National Pyrogov Memorial Medical University, Vinnytsia, Pyrogov 56, Vinnytsia, Ukraine
${ }^{2}$ Department of Pharmacy, National Pyrogov Memorial Medical University, Vinnytsia, Pyrogov 56, Vinnytsia, Ukraine

${ }^{3}$ Department of Eye Diseases, National Pyrogov Memorial Medical University, Vinnytsia, Pyrogov 56, Vinnytsia, Ukraine
\end{abstract}

\section{ARTICLE INFO \\ Received 09 August 2017 \\ Accepted 10 October 2017}

\section{Keywords:}

chronic hypokinesia,

physical endurance,

actoprotectors,

quinazoline derivatives,

2-ethylthiobenzimidazole

hydrobromide.

\begin{abstract}
The objective of the study was to assess the effect of a sodium salt 3-(2-oxo-3-phenyl$2 \mathrm{H}-[1,2,4]$ triazine[2,3-c]quinazolin-6-yl) of propanoic acid (MT-279 compound) on physical endurance of rats under conditions of chronic hypokinesia (15 days) in comparison with 2-ethylthiobenzimidazole hydrobromide (2-ETBI).

The results of the conducted experiment showed that chronic hypokinesia (15 days) caused a progressive decrease in the physical endurance of animals. The signs of this phenomenon occurred already on the Day 7 of the experiment. It manifested by a significant decrease in the duration of rats swimming, treadmill runtime and holding on rotating rods (rotarod test). The course of MT-279 compound ( $2.5 \mathrm{mg} / \mathrm{kg}$, ip) administered to animals in the specified experimental conditions contributed to restoration of physical performance of the study subjects. Upon introduction of the compound, the duration of rats' swimming on Day 7 of the experiment increased by $108.2 \%$, and on Day 15 by $64.2 \%$. Administration of 2-ETBI caused the growth of this indicator by $70.5 \%$ and $24.2 \%$, respectively. Along with this, we revealed an increase of rats ' treadmill running time. On Day 7 and Day 15 of the experiment, we recorded 55.2\% and $68.4 \%$ growth of the indicator, respectively. Daily administration of 2-ETBI contributed to $41.7 \%$ and $59.7 \%$ increase of running time, respectively.

On Day 7 of MT-279 compound administration under the conditions of chronic hypokinesia, the duration of rats' rod retention time increased by $58.7 \%$ compared to $6.2 \%$ for 2-ETBI. On Day 15 of the experiment, the physical endurance of animals assessed under this test compared to the control group was $89.0 \%$ and $72.3 \%$, respectively. On Day 7, MT-279 compound was significantly superior to the comparator drug in all tests performed for assessment of the ability to improve physical endurance under conditions of chronic hypokinesia. On Day 15 of study, the statistically significant superiority of MT-279 compound over 2-ETBI was identified in all forced swimming and rotarod tests.
\end{abstract}

\section{INTRODUCTION}

One of the leading factors of modern humankind morbidity is a sedentary lifestyle. The hypokinesia in most people is preconditioned by their professional work-style (office workers, computer operators, drivers, etc.) and limited motor activity due to injuries and/or illnesses [1,5]. Low level of motor activity like neurogenic stress causes activation of both the hypothalamo-pituitary-adrenal axis and nervous system. The continuous hypokinesia leads to various

\footnotetext{
* Corresponding author

e-mail: 16124sk@gmail.com
}

changes and morphofunctional disorders in a human body, such as atrophy of the musculoskeletal system, blood stasis, accumulation of fluid in organs and systems, decrease of immunity, etc. $[3,8,10]$.

Actoprotectors may be used to correct these disorders. These are medicines that improve physical endurance and performance of the body under normal and complicated conditions, inclusive of hypokinesia [7]. To date, the actoprotector class is limited to the only 2-ethylthiobenzimidazole hydrobromide (2-ETBI). Structural formula of 2-ETBI is given on figure 1 . 


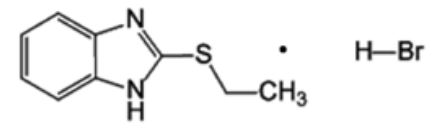

Figure 1. Structural formula of 2-ETBI

2-ETBI is manufactured in Russia under the trade name "Metaprot". Indications for use include increasing and restoring work capacity, adapting to the action of adverse factors, asthenic disorders [11]. This medicine has a number of side effects that limit its widespread use: facial hyperemia, gastralgias, etc. [7,11]. In this regard, the search for new chemicals with actoprotective properties for development of new medicines suitable for correction of hypokinesia, comes to the fore.

It was experimentally established that quinazoline derivatives are considered promising agents, capable of increasing the physical endurance of the body $[13,14]$. In the previous studies of 1,2,4-triazine-quinazoline derivatives, we established the presence of their expressive ability to increase physical endurance of rats under normal and complicated conditions. We experimentally identified the most active compound - a sodium salt 3-(2-oxo-3-phenyl-2H-[1,2,4] triazine[2,3-c]quinazolin-6-yl) of propanoic acid (MT-279 compound) [13]. Structural formula of MT-279 compound is given on figure 2 .

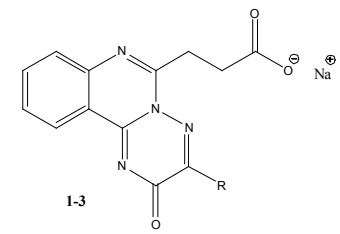

Figure 2. Structural formula of MT-279 compound

For deeper study of the MT-279 compound, it is expedient to study its ability to effect physical performance under chronic hypokinesia conditions.

The objective of the study was to assess the effect of the sodium salt 3-(2-oxo-3-phenyl-2H-[1,2,4]triazine[2,3-c] quinazoline-6-yl) of propanoic acid (MT-279 compound) compared to 2-ETBI in terms of physical endurance of rats under conditions of chronic hypokinesia.

\section{MATERIAL AND METHODS}

The study was conducted on 28 white laboratory 3-month rats of Wistar strain weighing 190-210 g. The animals were obtained from the vivarium of the National Pyrogov Memorial Medical University, Vinnytsia. The rats were kept on a standard water and food ration with free access to water and food and natural change of day and night. All interventions were conducted in compliance with the principles of the European Convention for the Protection of Vertebrate Animals used for Experimental and Other Scientific Purposes (Strasbourg, 1986), as evidenced by the opinion of the ethics commission of the Pyrohov Memorial Vinnytsia National Medical University (Minutes No. 7 dated 24 April 2014). The conditions of continuous hypokinesia were reproduced on the chronic immobilization stress model. Chronic immobilization stress was modeled by keeping animals in individual close-up canisters within 15 days (16 hours/day)
[4]. The rats were divided into 4 groups of 7 individuals each: I - intact animals; II - rats under conditions of chronic immobilization stress without treatment (control group); III - animals under conditions of chronic immobilization stress, administered a daily dose of MT-279 compound, $2.5 \mathrm{mg} / \mathrm{kg}$ (from Day 1 to Day 15), intraperitoneally (ip); IV - rats under conditions of chronic immobilization stress, administered a daily dose of 2-ETBI reference active agent, $33.0 \mathrm{mg} / \mathrm{kg}$, ip. The investigational substance and reference compound were used at $\mathrm{ED}_{50}$ doses under swimming test, calculated graphically by Litchfield-Wilcoxon method. Animals of the control group were administered an equivolumic amount of isotonic sodium chloride solution. The study compound, reference substance and pure solvent were administered to rats prior to placement in canisters.

The physical endurance of rats in the given experimental conditions was assessed by a forced-swimming test with an additional load (10\% by weight), that was fastened to the root of the tail in an atraumatic way. The research was conducted in a pool with a height of water layer not less than $60 \mathrm{~cm}$ under normothermia (water temperature $-24-26^{\circ} \mathrm{C}$ ). The duration ( $\mathrm{sec}$ ) of rats 'swimming was recorded until appearance of complete exhaustion signs, that was manifested in the refusal of further swimming and immersion of the animal under water [2]. We also used a treadmill animal run model (treadmill speed $-42 \mathrm{~m} / \mathrm{min}$, slope angle $-10^{\circ}$ ). The duration of rats run ( $\mathrm{sec}$ ) was measured until complete exhaustion, evidenced by negative reaction to stimulation by electrical charges $(40 \mathrm{~V})$ on the treadmill starting line [2]. The static endurance of animals was studied by a rotarod test with a 15-rpm rod rotation speed. We recorded time (sec) of holding rats on the rods [12]. For each test, animals were pre-adapted for 1-3 days of the experiment in order to get used to performing a certain load. The above studies were conducted on Day 7 and Day 15 of the experiment. These periods characterize the stages of resistance and depletion of the general adaptive syndrome [10]. The most distinct changes occur in the body in these terms of adaptation to stressful effects [10]. forced-sea and treadmill tests are dynamic jobs, but rotar test determines the coordination of movements, so the following sequence of testing was selected: forced swimming - rotarrod - treadmill. The break between tests for each of the experimental groups was 2 hours.

We processed the digital data of the study using the method of variation statistics and IBM SPSS Statistic 22 software, calculated a mean value $\mathrm{M}$, the arithmetic mean error $\mathrm{m}, \mathrm{t}$-Student criterion for normal distribution, nonparametric criterion $\mathrm{W}$ - for abnormal distribution, and Wilcoxon signed-ranked test $\breve{T}$ - to determine changes in the dynamics within the group. Statistically significant were considered the changes in parameters at $\mathrm{p}<0.05$.

\section{RESULTS AND DISCUSSION}

The results of the conducted study showed that chronic immobilization stress causes a progressive decrease in the physical capacity of animals in the control group. This phenomenon manifested by a significant decrease in the rats' swimming time (Table 1). 
Table 1. Effect of MT-279 compound and 2-ETBI on rats swimming time under conditions of chronic hypokinesia $(\mathrm{M} \pm \mathrm{m}$, $\mathrm{n}=7$ )

\begin{tabular}{|c|c|c|c|c|}
\hline \multirow{2}{*}{$\begin{array}{l}\text { Experimental } \\
\text { conditions }\end{array}$} & \multicolumn{2}{|c|}{ Day 7} & \multicolumn{2}{|c|}{ Day 15} \\
\hline & $\begin{array}{c}\text { Swimming time, } \\
\text { sec }\end{array}$ & $\begin{array}{c}\text { Trend, } \\
\%\end{array}$ & $\begin{array}{c}\text { Swimming time, } \\
\text { sec }\end{array}$ & $\begin{array}{c}\text { Trend, } \\
\%\end{array}$ \\
\hline Intact animals & $321.0 \pm 11.0$ & - & $355.3 \pm 25.3$ & - \\
\hline $\begin{array}{l}\text { Hypokinesia }+ \\
0.9 \% \mathrm{NaCl} \text { (control) }\end{array}$ & $140.9 \pm 3.6 \#$ & $-56.1 \mathrm{i}$ & $107.7 \pm 4.9 \#$ & $-69.7 i$ \\
\hline $\begin{array}{l}\text { Hypokinesia + } \\
\text { MT-279 }\end{array}$ & $293.3 \pm 12.3^{*} \omega$ & $+108.2 \mathrm{k}$ & $176.8 \pm 3.9 \# * \omega$ & $+64.2 \mathrm{k}$ \\
\hline $\begin{array}{l}\text { Hypokinesia + } \\
\text { 2-ETBI }\end{array}$ & $240.3 \pm 17.0 * \#$ & $+70.5 \mathrm{k}$ & $133.8 \pm 4.0 \# *$ & $+24.2 \mathrm{k}$ \\
\hline
\end{tabular}

The average swimming time in the group of intact rats was $321.0 \mathrm{sec}$ and $355.3 \mathrm{sec}$ on Day 7 and Day 15 of study, respectively. In contrast, the duration of swimming test in the control group test in the first phase of the experiment decreased by an average of $56.1 \%$ relative to intact animals (see Table 1). This trend also persisted on Day 15 of the experiment - the swimming time in this group of rats decreased statistically significantly by $69.7 \%$.

Physical endurance of animals, administered MT-279 compound to correct the chronic hypokinesia, statistically significantly increased compared to the control group at Day 7 of the experiment by $108.2 \%$. Daily administration of 2-ETBI in the specified experimental conditions also contributed to an improvement in the performance of animals relatively to control by $70.5 \%$. A similar picture persisted on Day 15 of study: as a result of MT-279 compound and 2-ETBI administration, the swimming time relatively to the control group statistically significantly increased by $64.2 \%$ and $24.2 \%$, respectively. At the same time, in the two milestones of study (Day 7 and Day 15), the MT-279 compound was significantly superior to the comparator drug (see Table 1).

The results obtained from assessment of the physical endurance in the treadmill test are shown in figure 3 . The mean of the rats' running time in the control group on Day 7 of study was $346.3 \mathrm{sec}$. This corresponds to a $27.2 \%$ decrease in efficacy compared to intact animals. On Day 15 of the experiment, the decline in physical endurance reached $36.7 \%$.

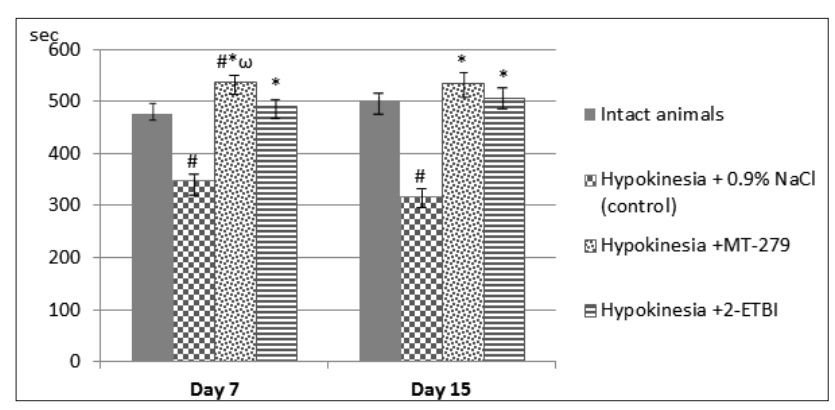

$*-\mathrm{p}<0.05$ relative to control; ${ }^{*}-\mathrm{p}<0.05$ relative to intact animals; $\omega-\mathrm{p}<0.05$ relative to 2 -ETBI

Figure 3. MT-279 compound and 2-ETBI effects on rats ' treadmill runtime under conditions of chronic hypokinesia $(\mathrm{M} \pm \mathrm{m}, \mathrm{n}=7)$;

It should be noted that the introduction of the test substance and reference compound to animals in the given conditions of the experiment contributed to the maintenance of physical endurance at the level of indicators of the intact group.
The course administration of MT-279 compound, as well as 2-ETBI, contributed to statistically significant increase of treadmill running time, as compared to the control group. For example, On Day 7 of the experiment, the animal running time increased by $55.2 \%$ and $41.7 \%$ respectively (see Fig. 3). On Day 15 of the study, the growth of physical endurance in rats assessed against the runtime indicator when administered MT-279 compound and 2-ETBI reached $68.4 \%$ and $59.7 \%$, respectively.

It should be noted that MT-279 compound was statistically significantly superior to the reference substance 2 -ETBI on Day 7 of study $(p<0.05)$ in terms of its ability to improve work performance under conditions of chronic hypokinesia. On Day 15 of the drug administration, MT-279 was equivalent in the efficiency with the compared drug (see Fig. 3).

The rotarod test of rats ' physical endurance confirmed the results of previous series of the experiment. The rod retention time in the control animals On Day 7 and Day 15 of chronic immobilization stress decreased by 81.7 and $66.4 \%$, respectively (Table 2).

Table 2. Effect of MT-279 compound and 2-ETBI on rats' rod retention time under conditions of chronic hypokinesia, $(\mathrm{M} \pm \mathrm{m}$, $\mathrm{n}=7$ )

\begin{tabular}{|c|c|c|c|c|}
\hline \multirow{2}{*}{$\begin{array}{c}\text { Experimental } \\
\text { conditions }\end{array}$} & \multicolumn{2}{|c|}{ Day 7 } & \multicolumn{2}{c|}{ Day 15} \\
\cline { 2 - 5 } & $\begin{array}{c}\text { Rod retention } \\
\text { time, sec }\end{array}$ & $\begin{array}{c}\text { Trend, } \\
\%\end{array}$ & $\begin{array}{c}\text { Rod retention } \\
\text { time, sec }\end{array}$ & $\begin{array}{c}\text { Trend, } \\
\%\end{array}$ \\
\hline Intact animals & $123.3 \pm 12.2$ & - & $119.0 \pm 2.8$ & - \\
\hline $\begin{array}{c}\text { Hypokinesia }+ \\
0.9 \% \text { NaCl (control) }\end{array}$ & $22.5 \pm 2.1^{*}$ & $-81.7^{i}$ & $40.0 \pm 5.7^{*}$ & $-66.4^{\mathrm{i}}$ \\
\hline $\begin{array}{c}\text { Hypokinesia }+ \\
\text { MT-279 }\end{array}$ & $35.7 \pm 1.8^{* \# \omega}$ & $+58.7^{\mathrm{k}}$ & $75.6 \pm 2.1^{* \# \omega}$ & $+89.0^{\mathrm{k}}$ \\
\hline $\begin{array}{c}\text { Hypokinesia }+ \\
\text { 2-ETBI }\end{array}$ & $23.9 \pm 1.4^{* *}$ & $+6.2^{\mathrm{k}}$ & $68.9 \pm 0.74^{* *}$ & $+72.3^{\mathrm{k}}$ \\
\hline
\end{tabular}

$*-p<0.05$ relative to control; $\#-p<0.05$ relative to intact animals; $\omega-\mathrm{p}<0.05$ relative to 2 -ETBI; $i-$ trend relative to intact animals; $k-$ trend relative to control.

The administration of MT-279 compound and 2-ETBI to animals in the given experimental conditions was accompanied by an increase of the endurance index in rats in both study milestones. On Day 7 of the study, MT-279 compound contributed to a $58.7 \%$ growth of the rod retention time. At the same time, the administration of 2-ETBI resulted in only $6.2 \%$ growth of the index. The positive effect of both substances was observed on Day 15 of the experiment. Thus, the course administration of MT-279 compound and 2-ETBI contributed to statistically significant growth of physical endurance of rats compared to the control group by $89.0 \%$ and $72.3 \%$, respectively. It should be noted, that MT-279 compound was significantly superior compared to the comparator drug in both milestones of the study (see Table 2).

Thus, the results of the study show that the laboratory designated MT-279 compound clearly improved the physical endurance of rats under conditions of continuous hypokinesia. This phenomenon confirms its actoprotective qualities in the complicated conditions of the experiment. Considering that MT-279 contributed to the maintenance of the ability to work in conditions of chronic immobilization stress, we can assume that it also has a stress-protective effect.

Attention is drawn to the fact that the substance under study, and 2-ETBI, mostly increase the endurance of rats in the test run in treadmill.By magnitude of the indicated actoprotective effect, the study medicine was statistically 
significantly superior to the comparator drug on Day 7 in all tests performed. On Day 15 of the study, the MT-279 compound demonstrated statistically significant superiority over 2-ETBI in both forced swimming and rotarod tests.

According to the literature [10], the influence of any stressor factor causes a general adaptive syndrome in a (human) body. Day 15 of chronic immobilization stress corresponds to the exhaustion stage of the general adaptive syndrome. This period is characterized by the predominance of catabolic processes over anabolic ones $[6,10]$. Having analyzed the obtained data, we can assume that the effect of the sodium salt 3-(2-oxo-3-phenyl-2H-[1,2,4]triazine[2,3-c] quinazoline-6-yl) of propanoic acid (MT-279 compound) is associated with the ability of the substance to inhibit catabolic processes in organism of rats under conditions of chronic immobilization stress. This phenomenon was confirmed by the results of study of MT-279 compound effect on energy, carbohydrate and protein metabolism, obtained by us in previous experiments [9]. In view of the results, the sodium salt 3-(2-oxo-3-phenyl-2H-[1,2,4]triazine[2,3-c] quinazoline-6-yl) of propanoic acid (MT-279 compound) may be considered a promising subject for further in-depth research.

\section{CONCLUSIONS}

1. Amtage F. et al. Hypokinesia upon pallidal deep brain stimulation of dystonia: support of a GABAergic mechanism. Front. Neurol., 1-6, 4, 2013. DOI: 10.3389/fneur.2013.00198

2. Contarteze R.V. et al. Stress biomarkers in rats submitted to swimming and treadmill running exercises. Comp. Biochem. Physiol. Part A: Mol. Integr. Physiol., 415-22, 151, 2008. DOI: dx.doi. org/10.1016/j.cbpa.2007.03.005

3. Kim H. G. et al. Effects of treadmillexercise on hypoactivity of the hypothalamo-pituitary-adrenal axis induced bychronic administration of corticosterone in rats. Neurosci. Lett., 46-49, 434, 2008. DOI: doi.org/10.1016/j.neulet.2008.01.025
4. Lucak I. V. et al. Stress-protective properties of the extract of the aspen cortex and its influence on the adrenocortical histology on the model of immobilization stress. Vrach-aspirant, 290-297, 3.2, 2013. Retrieved from: http://vrach-aspirant.ru/articles/ pharmacology/13173/

5. Mak M. K. Y. Reduced step length, not step length variability is central to gait hypokinesia in people with Parkinson's disease. Clin. Neurol. Neurosurg., 587-590, 5, 2013. DOI: 10.1016/j. clineuro.2012.07.014.

6. Margolis L. M., Rivas D. A. Implications of Exercise Training and Distribution of Protein Intake on Molecular Processes Regulating Skeletal Muscle Plasticity. Calcif. Tissue Int., 211-221, 3, 2015.

7. Oliynyk S., Oh S. The Pharmacology of Actoprotectors: Practical Application for Improvement of Mental and Physical Performance. Biomol. Ther., 446-56, 20(5), 2012. DOI: 10.4062/ biomolther.2012.20.5.444

8. Pierre N. et al. Derbre. From physical inactivity to immobilization: dissecting the role of oxidative stress in skeletal muscle insulin resistance and atrophy. Free Radic. Biol. Med., 197-207, 98, 2016. DOI: https://doi.org/10.1016/j.freeradbiomed.2015.12.028

9. Saenko A. V., Zaichko N. V., Stepanyuk G. I. Effect of sodium salt of 3-(2-oxo-3-phenyl-2H-[1,2,4]triazine[2,3-c]quinazolin6 -yl) propanoic acid and bemityl on biochemical processes in rats organism in the conditions of the daily training with running in treadmill. Curierul Med., 31-36, 57(6), 2014.

10. Selye H. (1974). Stress without Distress. Philadelphia: Lippincott.

11. Shabanov P. D. Neuroprotector Metaprot: mechanism of action and new clinical directions of use. Consilium Med., 2010; 12(2): 140-144.

12. Shiotsuki H. et al. A rotarod test for evaluation of motor skill. J. Neurosci. Methods, 180-85, 189(2), 2010. DOI: 10.1016/j. jneumeth.2010.03.026

13. Stepanyuk G. I. et al. Screening of actoprotective activity among derivatives of quinazoline and its condensed analogues. Pharmacol. Drug. Toxicol., 60-63, 4(17), 2010.

14. Toziuk O. Yu. Actoprotective action of sodium 2-(tetrazol[1,5-c] quinazolin-5-ylthio)acetate in acute hemic hypoxia. Zaporozhye Med. J., 12-14, 1(100), 2017. DOI:10.14739/2310-1210.2017.1.91722 